\title{
3D scanning, modeling, and printing of Chinese classical garden rockeries: Zhanyuan's South Rockery
}

\author{
Qianli Dong, Qingping Zhang ${ }^{*}$ (1) and Lingxi Zhu
}

\begin{abstract}
Chinese classical garden rockeries have rich historical and cultural value, as they are a part of China's cultural heritage. In recent years, while the digital research of rockeries has increased, most of it is limited to a rockery's digital record. However, other issues have not been thoroughly discussed, such as how to digitally protect a rockery, activate it as an immovable, solid site heritage by digital means, and transform its function. To ensure the effectiveness of rockery data, this paper compares the advantages and disadvantages of digitally mapping the Huanxiu Shanzhuang rockery, which was conducted by the team at an early stage, to a convenient and accurate digital rockery data acquisition scheme that was used for the Zhanyuan South Rockery, as an example of carrying out three-dimensional digital mapping. Furthermore, from the perspective of the sustainable development of cultural heritage, this study attempts to print Chinese classical garden rockeries in three dimensions to realize their physical representation. This paper aims to provide a new way to activate, restore, and protect rockeries.
\end{abstract}

Keywords: Chinese classical garden, Zhanyuan South Rockery, Terrestrial laser scanning, 3D printing, Sustainability

\section{Introduction}

As a solid heritage site, the Chinese classical garden rockery was systematically introduced by Murck and Fong as early as 1980 [1]. Next, Yu et al. [2], Paolillo et al. [3], and Keswick et al.. [4] described the details of rockeries more clearly; Parkes [5] pointed out that the love for rocks in Chinese culture is unique; and Aplin [6] proposed that the rockery has a strong representation in Chinese classical gardens. The heritage and cultural value of rockeries have been fully discussed all over the world. In recent years, with the wide application of 3D scanning technology in the field of cultural heritage [7-9], some scholars have made attempts to use 3D digital technology to map and record rockeries. For example, Zhang et al. have systematically demonstrated the feasibility of 3D laser scanning and close-range photogrammetry for

*Correspondence: Zhangqingping2015@163.com

College of Landscape Architecture, Nanjing Forestry University, Nanjing, Jiangsu, China landscape mapping [10]. Yang et al. have carried out systematic mapping and an analysis of the Yu Garden rockery by using a 3D laser point cloud [11]. Wen Ning [12] obtained accurate drawings of the Jingyi Garden rockeries through digital mapping technology. Finally, Chen Wanyu [13] has used the finite element method to preliminarily explore the 3D stacking of a rockery. Overall, many teams have achieved substantial research on digital data acquisition of rockeries and carried out digital research by using a data model. However, several studies on digital rockeries have focused only on the digital acquisition of a rockery and the digital model's analysis. These studies do not entail an in-depth discussion of the physical representation of the digital model.

Since Chinese classical garden rockeries are part of China's cultural heritage, they belong to the category of a cultural landscape. Therefore, the protection and research of rockeries need to be based on the World Heritage Committee's concept of a cultural landscape. According to the definition in UNESCO's 2013 edition of the guidelines for implementing the World Heritage 
Convention [14], cultural landscapes must be evolutionary and sustainable. As a cultural landscape, measures for protecting rockeries must begin by being sustainable. The digitization of heritage is widely used as an effective means for achieving sustainable development. Through digitization, a rockery can be simulated three dimensionally. However, according to Zanola et al., people are more inclined to provide access to an actual artifact than provide a virtual substitute [15]. For rockeries, digital technology saves the model information, but from the perspective of intuition and learning, a solid display is more advantageous than a virtual 3D model.

Since they have a solid-state heritage, rockeries significantly impact their sustainability without digitalization:

(i) Rockeries are different from small-scale cultural relics, as they have large-scale, solid-state heritage, which cannot be displayed on the move. Tourists and researchers, for example, can only contact a rockery through field investigation.

(ii) Unlike most buildings, rockeries are not made of wood or bricks. While bricks and wood need secondary processing when building houses and can be produced in a mold or formed to standard, the rocks used for the rockery are all from nature and are natural shapes. In nature, each rock is as unique as a snowflake. Therefore, when the mountain is damaged, and the rock is broken and lost, they are difficult to rebuild.

(iii) Some rockeries are not open to visitors because of serious damage and their extensive history.

Thus, a rockery without a digital carrier cannot interact with people well, as its cultural base is largely blocked to the public, and its sustainability as a cultural landscape is significantly affected. Since the classical garden lost its function of serving the literati, the rockery, one of the garden elements, must continue to be activated by evolving to meet the needs of both the public and cultural landscape.

Issued by Henry Cole in 1867, the Convention for Promoting Universally Reproductions of Works of Art for the Benefits of Museums of All Countries [16] is dedicated to the reproduction of artworks. Through physics, these works evolve and are reproduced through sculpture, photos, and other means that do not harm the original. Therefore, the rockery should also be a part of this sustainable process of evolution by utilizing physics. Since the rockery is too large and the stone's height is irregular, it cannot be physically shaped through direct sculpture. Also, because of strong participation, its function as an image carrier does not have an intuitive effect. Digital information should be used to make a rockery into a physical carrier. In other words, digital means should be gradually transformed from having archival purposes to achieving physical representation, so that it can intuitively serve more people while ensuring the sustainability of its cultural value.

As a form of a digital model carrier, 3D printing has been used to protect cultural heritage [17] —for example, in restoring historical buildings [18-21] and cultural relics [22]. A 3D-printed model plays an important role in protecting the rockery. Just as historical buildings are constantly being damaged by natural and human factors (e.g., air pollution [23] and mechanical loads [24]), Chinese classical garden rockeries are also constantly exposed to outside elements through the year, so they are affected by natural factors, including sunshine, rain, wind, as well as man-made factors such as tourists' climbing. Since most rockeries face local collapse, weathering, seepage, and other natural factors caused by damage to the mountain, they must be intermittently or permanently closed for the sake of heritage protection and detection, which means that visitors cannot experience close contact with the rockery. A rockery model obtained through 3D printing can build models of different scales. Because of its degree of replicability, this part of the model can be displayed to visitors throughout the year and can even be disassembled. Moreover, whereas the rockery originally belonged to an immovable heritage site, its digital copy can be moved (to a certain extent) in the form of digital media re-materialization. This would ensure its cultural transmission and promote the possibility of a cultural landscape's sustainable exhibition across the world.

Lim et al. tested medical undergraduates who had not received teaching in cardiac anatomy and found that the examination scores of the students who used a threedimensional printed biological model for self-directed learning increased by $60.8 \%$ [25]. This score was significantly higher than that of the students who used cadaveric materials or combined materials for self-directed learning, which demonstrates its operability in education. For rockery researchers, by restoring the original appearance of rockeries to the greatest possible extent, 3D models can assist learning and studying. Not only will this method ensure data authenticity, but it will also avoid the possibility of damage that could be caused by multiple researchers having direct contact with the rockeries. Moreover, 3D printing models can be displayed and collected in museums. Through industrial reproduction [26], new forms of cultural heritage analysis and results may be developed as well and provide global opportunities for studying rockeries.

Currently, there is copious research on use of 3D printing to preserve cultural heritage, such as 3D scanning and modeling by UAV (Unmanned Aerial Vehicle) 
photogrammetry $[27,28]$. However, the rockery is covered with a large number of plants. When using UAV photogrammetry, an abundance of plant leaves and branches seriously affect the accuracy of measurement and render a large number of areas unable to be photographed because of plant occlusion; thus, it is impossible to rely on UAV Photogrammetry for 3D scanning and printing models. In recent years, however, 3D printing costs have gradually reduced, while the number of $3 \mathrm{D}$ printing products has increased. In their work, Wabinski and Moscicka state that most currently produced models are only decorative, which is not conducive for planning and research [29]. A 3D-printed model should, to the greatest extent, recreate the original appearance of the site to ensure the authenticity of its products and restore part of the cultural heritage's research value. Therefore, follow-up research can be conducted around these products to prevent damaging the heritage and ensure the continuous copying of its printed products.

According to our knowledge, there currently seems to be no research on the 3D printing of rockeries; this fact is primarily due to the difficulty in obtaining from the rockery because of the complexity and diversity of its shape. In other words, the accuracy of the data is dependent on the 3D printing model's accuracy as well. Therefore, this study attempts to carry out high-precision processing on the model during the data acquisition stage as well as the $3 \mathrm{D}$ printing stage, respectively, to ensure that the model has a similar level of detail with the heritage site. The model can replace some functions of the heritage site as it could be utilized in such fields as education and tourism to ensure the sustainability of its cultural heritage. Furthermore, there is no systematic and theoretical discussion on applying 3D printing in rockeries either. To this end, this study selects the Nanjing Zhanyuan South rockery to discuss the feasibility of 3D printing. Through 3D scanning and 3D printing, this study obtains a complete and systematic 3D scanning scheme.

While most existing research focuses on stand-alone ground laser scanning [30] and digital photogrammetry [31], the 3D scanning modeling of a private garden is primarily based on terrestrial $3 \mathrm{D}$ laser scanning or a combination that includes UAV photogrammetry as well as other schemes [32]. Most of these studies discussed data collection and archiving but did not discuss how to display data in different ways, such as through 3D printing. Different display methods determine the accuracy of data at the acquisition stage. None of these schemes is aimed at 3D printing, however; thus, the equipment, instruments, and mapping methods are based on a single mapping target, which is not how the rockery is most often utilized because of its complex surface texture and environment. For example, most of the private garden rockeries south of the Yangtze River have rich cave and gap changes. For the terrestrial 3D laser scanner, most of the cave areas are too small to be scanned, preventing the obtainment of point cloud data with increased accuracy. The results of $3 \mathrm{D}$ printing and secondary scanning should meet the needs of the scientific research team. Therefore, the 3D laser scanning scheme for 3D printing should also combine a terrestrial 3D laser scanner and a hand-held 3D laser scanner. Since these data sets are complementary, we can obtain complete and accurate 3D data sets of rockeries to print.

\section{Research aim}

This paper introduces a new scanning and model processing method for Chinese classical garden rockeries to conduct 3D printing. Based on the team's early experience scanning Huanxiu Shanzhuang, this paper analyzes the advantages and disadvantages of the methods that were used and improves the 3D scanning method for rockeries. The aim, therefore, is to simplify the scanning process, reduce the scanning time, and improve scanning efficiency and accuracy, which could help facilitate later research. This paper puts forward the novel idea of the three-dimensional printing of rockeries in order to assist in their future restoration, provide increased opportunities for studying them, and protect them (e.g., rescue protection and preventive protection) from natural and man-made changes that are a result of open-air conditions.

\section{Materials and methods \\ Study site}

Zhanyuan, one of the four famous gardens in the Jiangnan area of China, is located in Nanjing. It was built during the Jiajing period of the Ming Dynasty, and its spatial layout and gardening techniques are typical of the private gardens in Jiangnan. Zhanyuan has Jingmiao hall in the center with a long corridor, and the layout is also equipped with pavilions, a windowed veranda, waterside pavilions, and other garden buildings to create a rich and varied garden space. There are two rockeries in the south and north of the courtyard, which are located on the north and south sides of Jingmiao hall. The southern rockery was built by Liu Dunzhen, a famous Chinese architect [33].

The overall shape of the mountain surrounds the lower front portion of the rockery and the higher backend as well. The peaks and mountains make up dispersed front and back layers with stone walls that are vertically divided by grooves. Thus, the limestone texture in other natural mountain walls is consistent. According to the principle dome structure, a cave is built on the stone wall, and an artificial waterfall is constructed alongside plants, making it appear like a valley in the mountains (Fig. 1). 


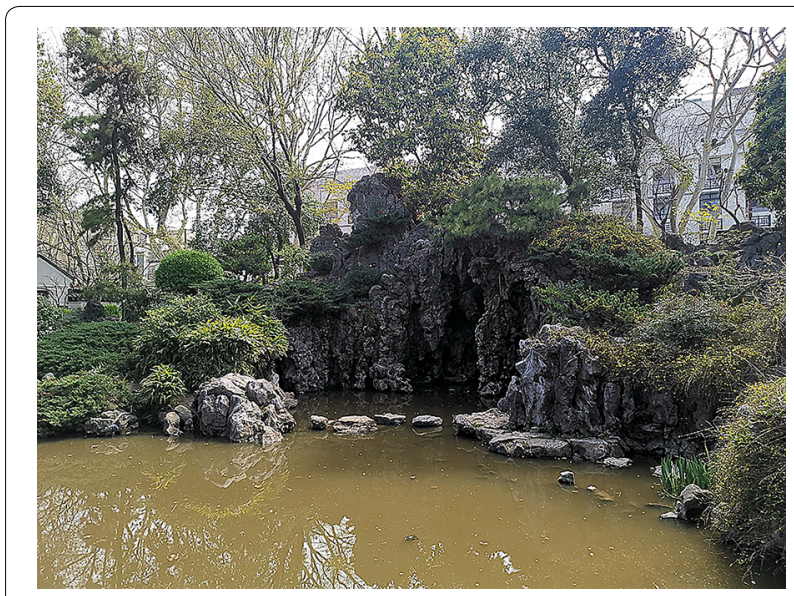

Fig. 1 Zhanyuan's south rockery

\section{Target-free 3D scanning method}

In an early stage, the team performed a 3D scan of Suiyuan and Huanxiu Shanzhuang. By setting up the station, they were able to acquire field data from the 3D laser scanner, the Leica ScanStation C10. According to different garden-building elements, sweeping sites were set up for the whole garden. To splice point cloud data at a later stage, the scanning targets should be established as the site is being set up in the early stage in order to register the point cloud. During the scanning process of Suiyuan, thirteen scanning sites and thirteen scanning targets were set up. In Huanxiu Shanzhuang, however, eighty-nine scanning sites and sixty-one scanning targets were established, including twentytwo stations and ten targets in the main rockery area (Fig. 2).

During the scan of the entire Huanxiu Shanzhuang site, the target and site could not be set in the deep cave of the rockery and the narrow spaces, such as the stone joint, because of the site's space limited for setting up the scanning target. The registration accuracy of the point cloud is affected by the number of targets. In the later stage, when using Cyclone (software for processing point cloud data) to match the point cloud on time, there were some problems in the rockery of Huanxiu Shanzhuang, such as the staggered stone area, leaks in the splicing process, and coordination confusion (Fig. 3). In the later stage, when the point cloud model was refined, manual registration was needed in areas that had fewer scanning targets (e.g., mountain caves), which resulted in a large error. Therefore, from the researcher's perspective, it is feasible to use the 3D laser scanner with the scanning target type data acquisition method for researching a park's landscape elements. However, for a rockery with a single garden element,

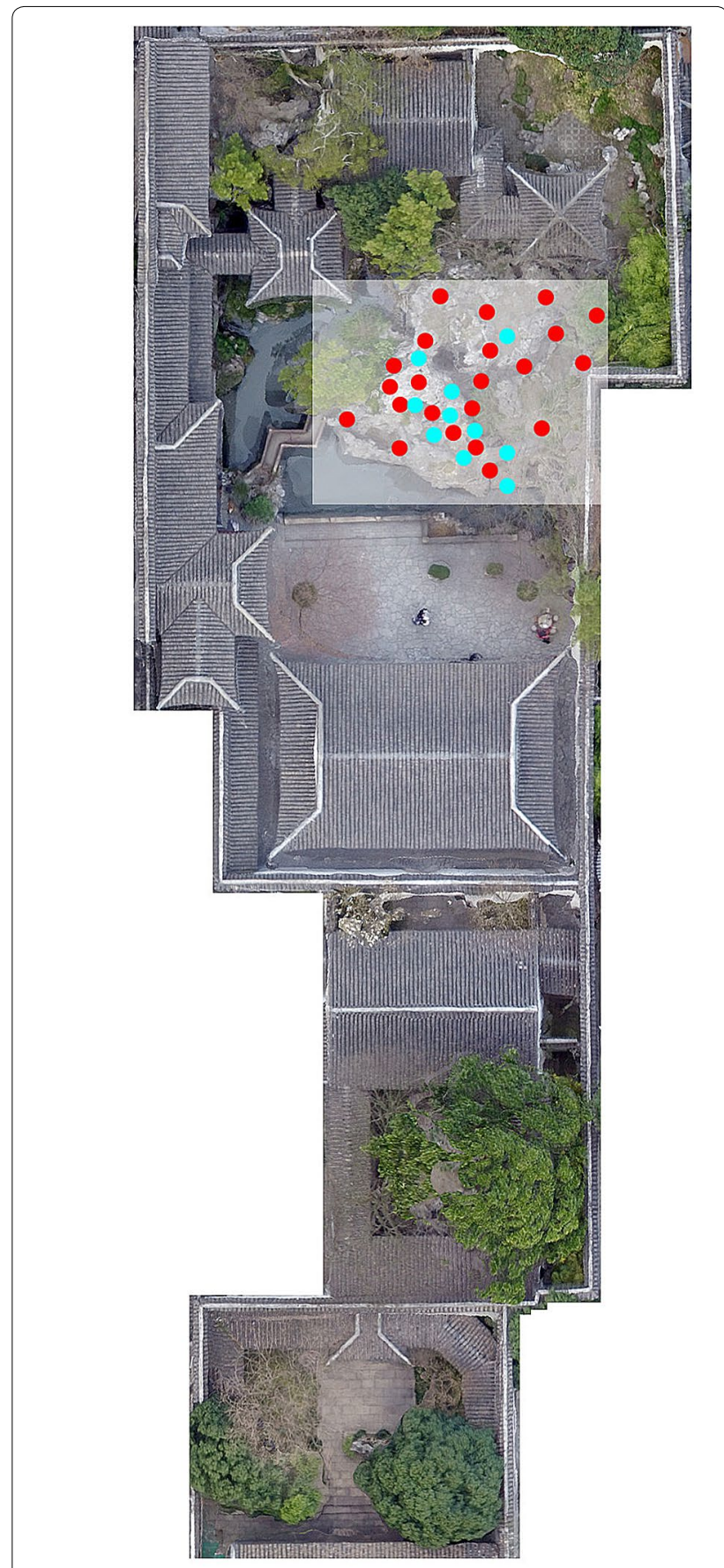

\section{Stations Targets}

Fig. 2 Stations of Huanxiu Shangzhuang

the accuracy of digital rockery research is limited by an early field operation error.

To avoid the problems caused by Huanxiu Shanzhuang scanning and further improve the scanning 


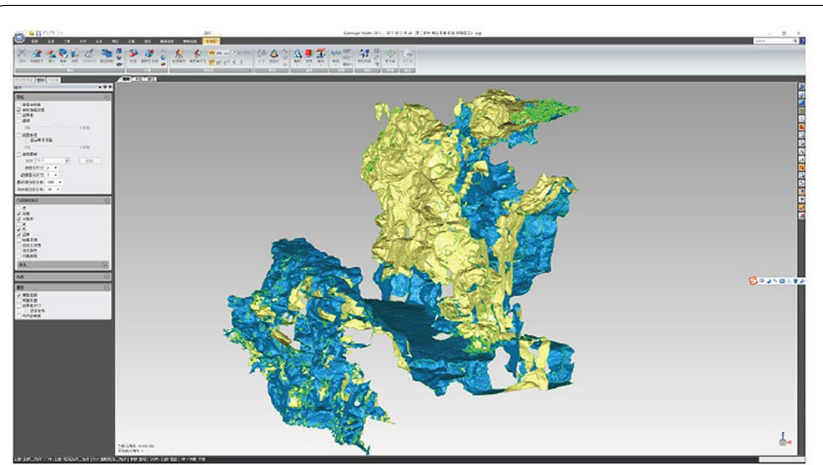

(a)

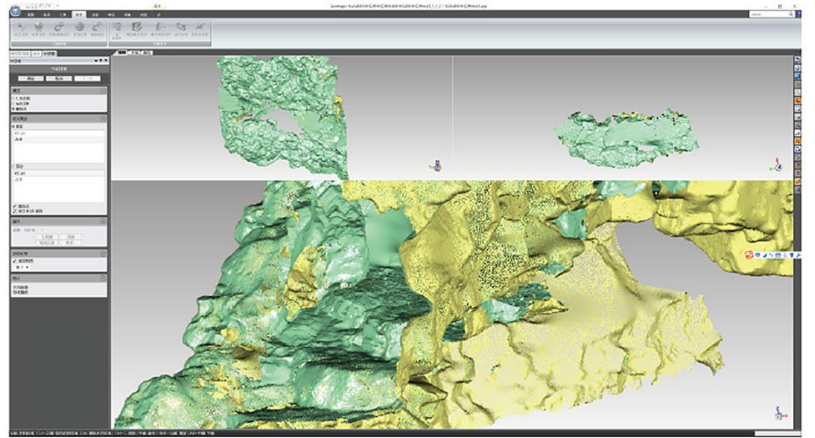

(c)

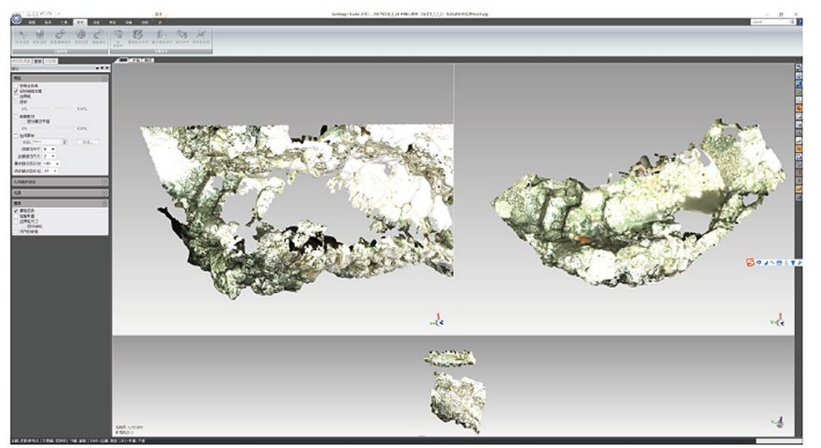

(b)

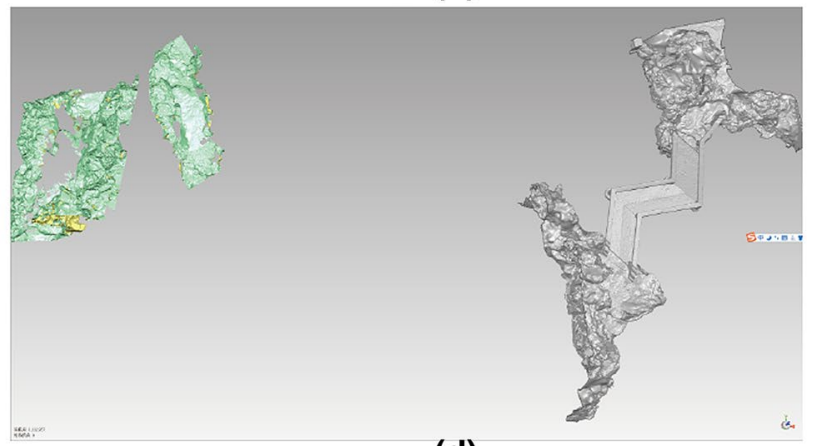

(d)

Fig. 3 Huanxiu Shanzhuang modeling problem. a The front and back of the rockery are interlaced. $\mathbf{b}$ There is a hole in the surface of the mountain. c Stone crossing in some areas. $\mathbf{d}$ Coordinate confusion

accuracy, this experiment adopts a target-free 3D scanning method to avoid the problem of limited data accuracy caused by a target that cannot be placed. The object of this data collection is the South Rockery of Zhanyuan, which remains a complex space. Since the surrounding plants provide ample cover with dramatically changing heights, most areas are difficult to walk through. Meanwhile, because of the demand of the Chinese classical garden's construction method, it is closely connected with the surrounding environment, and a large number of rockery components are shielded from each other. This environment cannot use a conventional data acquisition method, such as UAV aerial photography or photogrammetry. Although the stand-alone 3D laser scanner can ensure the data's high accuracy, the complexity of the rockery and occlusion between the landscapes render many areas of the mountains difficult to either stand or scan. Moreover, the rockery is primarily composed of Taihu stone (a type of stone from Lake Tai, in the western part of Suzhou, China, which has a variety of forms, many holes and textures on its surface, and often appears in classical gardens), and so the surface has caves and an extremely complex texture. Relying only on the terrestrial 3D laser scanner means that there will be similar problems with surveying and mapping Huanxiu Shanzhuang and Suiyuan.

To avoid these problems and collect sufficiently accurate rockery data, this study attempts to use a hand-held 3D laser scanner for mapping. Compared to the standalone scanner, the hand-held scanner is highly flexible, and it can operate in local fine areas without setting up a station. Although it has a high operability capacity for caves, cliffs, areas with complex structures, and narrow spaces, the accuracy of the data acquisition is lower than the stand-alone 3D laser scanner; its surveying and mapping range meets the surveying and mapping needs for a small rockery less than 100 meters in length. Therefore, to meet the demands of 3D printing, this study adopts the multiple data acquisition method by utilizing a terrestrial 3D laser scanner and a hand-held 3D laser scanner to conduct data acquisition for Zhanyuan's South Rockery. This includes the advantages of the two surveying and mapping methods, complements the data, and meets the modeling requirements. To ensure the accuracy of the scanning data while using the two scanners together, the main body of the large rockery was scanned with the stand-alone 3D laser scanner and then supplemented by the hand-held backpack 3D laser scanner. The data will 
be supplemented for areas whose stand-alone data cannot be collected.

The equipment used in this study was a terrestrial Trimble TX8, which has an acquisition accuracy of $1 \mathrm{~mm}$, a scanning distance of $18 \%$ of the target reflectivity (above $335 \mathrm{~m}$ ), and a measurement speed of $1,000,000$ points per second; its price is $\$ 115,000$ USD. The hand-held, knapsack GeoSLAM ZEB HORIZON was also used; its mapping distance can reach $100 \mathrm{~m}$ with a scanning speed of 300,000 points per second and an acquisition accuracy of $10-30 \mathrm{~mm}$, and its price is $\$ 85,000$ USD. The whole collection area of the rockery is about $2200 \mathrm{~m}^{2}$, and the large volume is covered by many plants. The main part of the rockery was collected using the Trimble TX8. Because of the intersection and shielding of the rockery's various landscape elements, components, and irregularities during the process of erecting the rockery, to comprehensively obtain all sides of it, the hand-held scanning operation is added as well.

Because the surface of Taihu stone has an extremely complex texture and presents a porous structure, it is necessary to include multiple sites from different angles to scan every face and cranny of the rock completely. Also, because the rockery surface is covered with a large number of plants that seriously affect the actual distance of scanning and blocks the laser, an increase in the number of stands was made to ensure the complete scanning of all corners of the rockery. The total number of large-scale stations was 154 (Fig. 4). The scanning time was $3.5 \mathrm{~h}$, and the total number of cloud collection points was approximately 1.66 billion. Since the narrow area and cave cannot be accessed or blocked from too much scanning information, the hand-held GeoSLAM ZEB HORIZON scanner was used to scan the details of the rockery for a short distance; however, this process does not necessitate setting up a station. The researcher carries out a full range of laser scanning to capture the

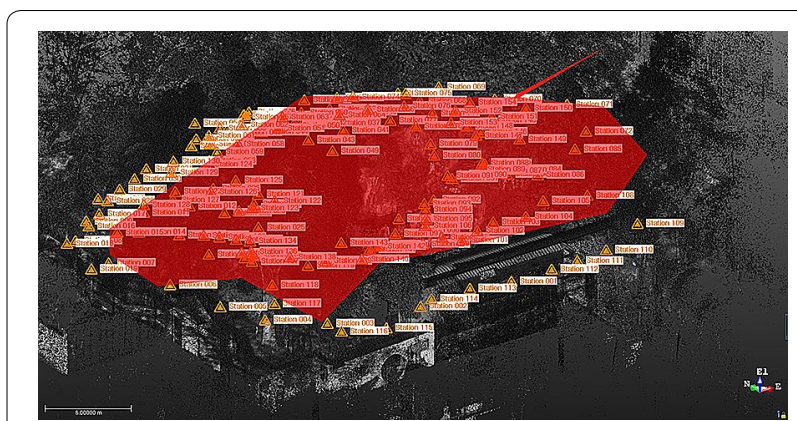

Fig. 4 Zhanyuan's South Rockery stations (the red area is the target rockery area) object through a hand-held scanning instrument. The overall scanning time is forty minutes, and the total number of points is about 320 million.

\section{Automatic splicing data processing without targets}

Preprocessing the point cloud data followed the field data collection. Matched with the Trimble TX8, the Trimble RealWorks (TRW) software, which can preliminarily splice point cloud data, was used for processing. To avoid the problem of automatic data splicing at a later stage (due to the target being unable to set, which affects the accuracy of scanning data), the Trimble TX8 and the TRW software can realize fully automatic splicing without a target and automatically calibrate based on the degree of overlap between the cloud data from each site. Since the object of the 3D scanning is a rockery (compared to scanning the entire garden space), the research conducted for this study involves the overlapping of rocks and the surface's texture to maintain high scanning precision.

In the process of surveying and mapping Huanxiu Shanzhuang, the spatial range was large since the research object included the entire garden; thus, the data accuracy was not high. In the mapping process of acquiring rockery data, the Leica ScanStation C10 had to maintain the instrument balance during the process of erecting the station. Since the rockery surface was mostly uneven and the site's setting was limited, it was impossible to comprehensively scan every surface of the Taihu stone in the rockery. All of the data, therefore, could only be calibrated by the scanning target. Therefore, in the post-processed data, many holes remained in the rockery that need to be completed manually, which greatly reduces the accuracy of the research.

To ensure accurate data acquisition in all areas of the rockery during the scanning process, the number of stations at different angles was increased to 154 during the set-up process. Comprehensive data acquisition and data reconnection between the stations was achieved by ensuring point cloud calibration during the later stage. Also, the Trimble TX8 did not require an absolute level during the scanning process; thus, more stations could be set up on the rockery's surface. Meanwhile, this instrument could cooperate with the hand-held Slam_Horizon scanner to further guarantee comprehensive data. The complete data splicing process took fifteen hours. The final average splicing accuracy was $2.67 \mathrm{~mm}$, and the total number of points was 1.66 billion.

Based on aerial photos and preliminary point cloud splicing results, Zhanyuan's South Rockery cannot be identified or studied because it is shrouded by plants. Therefore, after the point cloud preprocessing stage, 
it is necessary to classify the point cloud to exclude the impact that plants have on the rockery. The point clouds of the rockery and vegetation are automatically classified in the TRW software, which took an hour, approximately. Since the rockery is covered with shrubs, some are automatically identified as rockery and ground. Therefore, after the software's automatic calculation is complete, one further step of data precision treatment is needed; the model needs to be manually refined to eliminate the impact of shrubs on the rockery while retaining the trunk and roots of some trees to avoid leaving a ground cavity. The whole model's precision treatment time takes eight working days.

After finishing the point cloud classification, the triangle network model should be calculated next. Since the point cloud contains ample plant information, there will be model dislocation and other errors during the calculation process of the triangular network model, which need to be manually repaired. In this stage, the TRW software automatically filters the remaining shrubs to include rockery information in the model, which takes six working days. During the scanning process, the rockery was made-up of overlapping stones. Generating the software grid model would have rendered avoiding the occurrence of some small holes impossible; therefore, one step of the data precision treatment, the process is to repair the model manually, was needed. Finally, it took six working days to repair the rockery and complete the Trimble TX8 fine scanning process of the whole rockery model (Fig. 5).

\section{Results and discussion \\ Data merging}

The hand-held GeoSLAM ZEB HORIZON 3D scanner is primarily responsible for gathering field data in narrow areas (e.g., caves, stone seams, hole, and plant-filled areas) that cannot be scanned by the Trimble TX8. Since the Slam_Horizon does not require setting up a station, it can conveniently maintain both the initial and endpoints at the same location. The data collection took forty minutes, and the total number of acquired points was approximately 320 million. The subsequent point cloud processing steps of the Slam_Horizon are the same as the Trimble TX8's data processing steps. By aligning the processed Slam_Horizon and the Trimble TX8 models, the two data sets can be complementary. The merge process also used TRW. In this process, the overlapping parts of the point clouds of the two models are identified to realize automatic splicing; this means that it is not necessary to manually select the coordinates of the feature points and the target. At an intersection of small cracks, for example, the Slam_Horizon obtained the data that the Trimble TX8 cannot obtain, and finally, the two data sets complement each other to complete the point cloud data model of Zhanyuan's South Rockery (Figs. 6, 7 and 8). The accuracy of the combined model remains at the millimeter level.

\section{D printing}

Because of the large volume of the entire model (approximately $750 \mathrm{~m} 2$ ), printing the rockery in 3D entailed selecting a relatively complex area of the

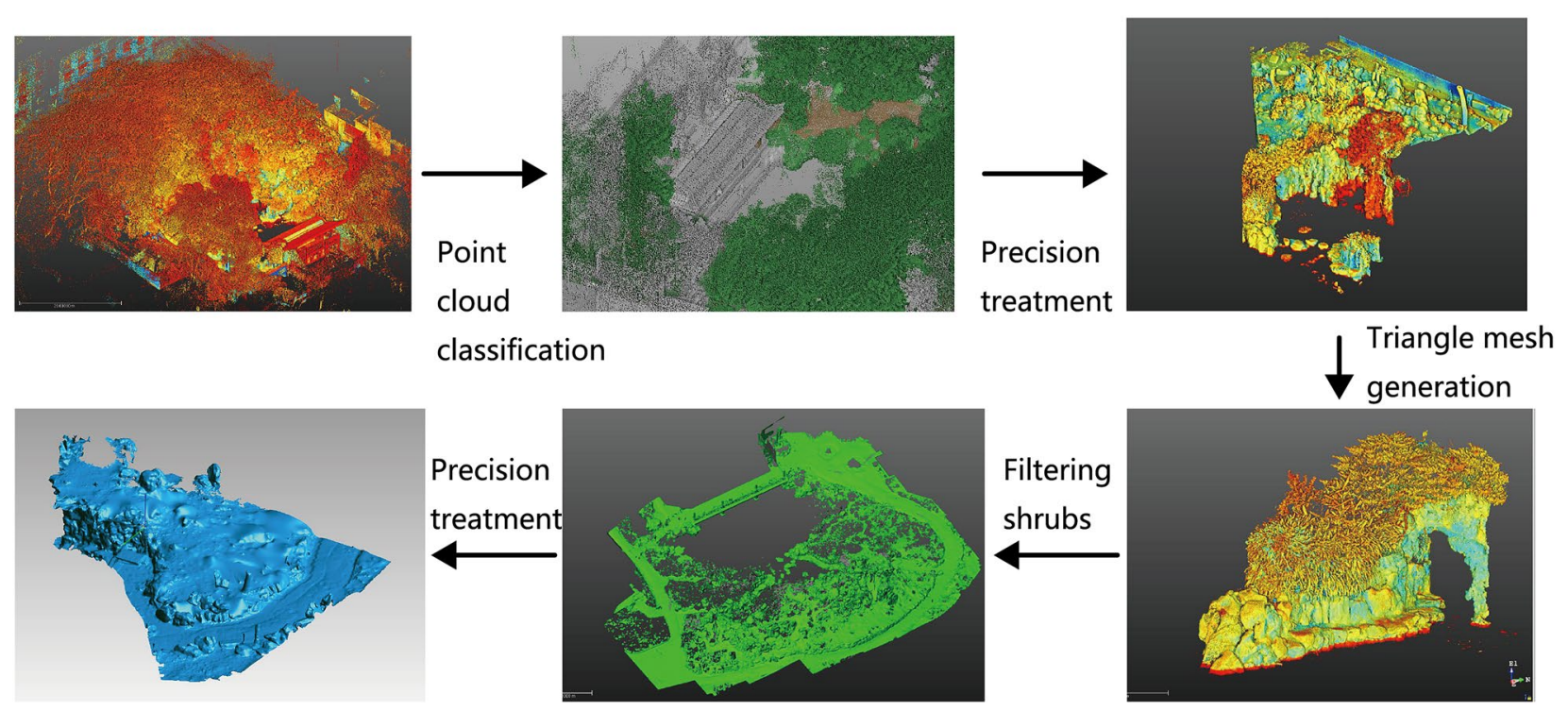

Fig. 5 The Trimble TX8 model process procedure 


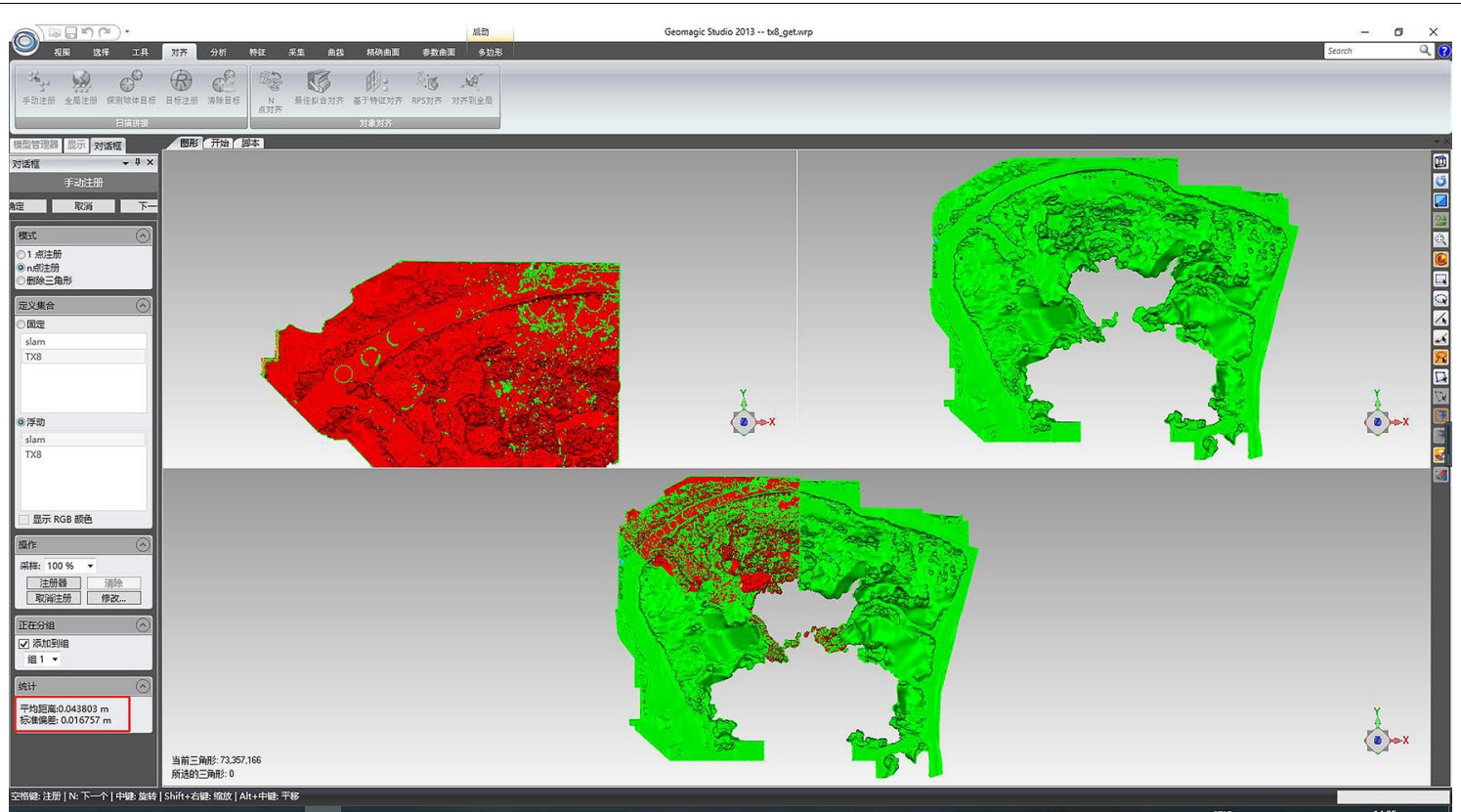

Fig. 6 The model combination of the Trimble TX8 and Slam_Horizon (with the Slam_Horizon data in red, and the Trimble TX8 data in green)

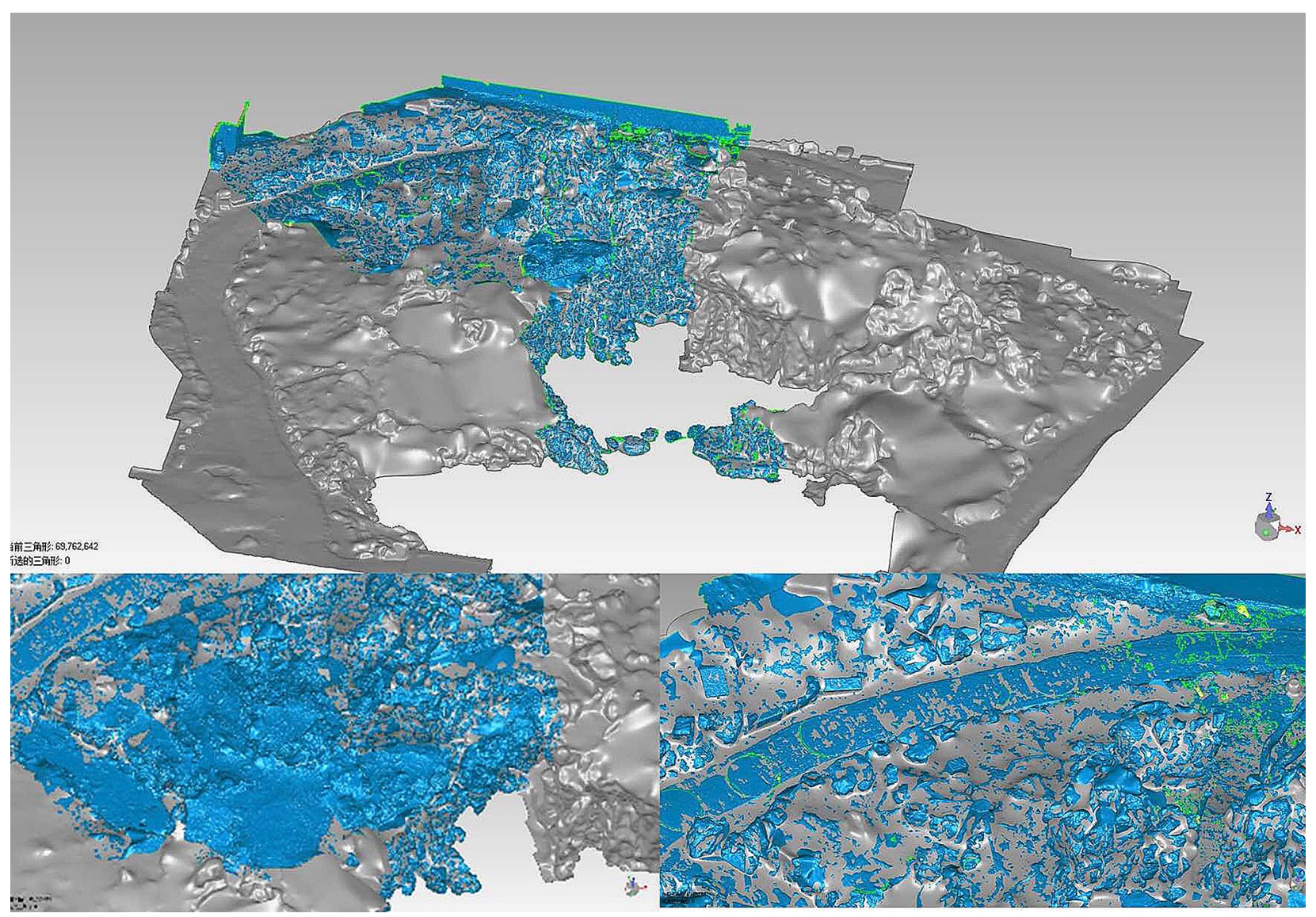

Fig. 7 The combined model (with the Slam_Horizon data in blue, and the Trimble TX8 data in gray) 

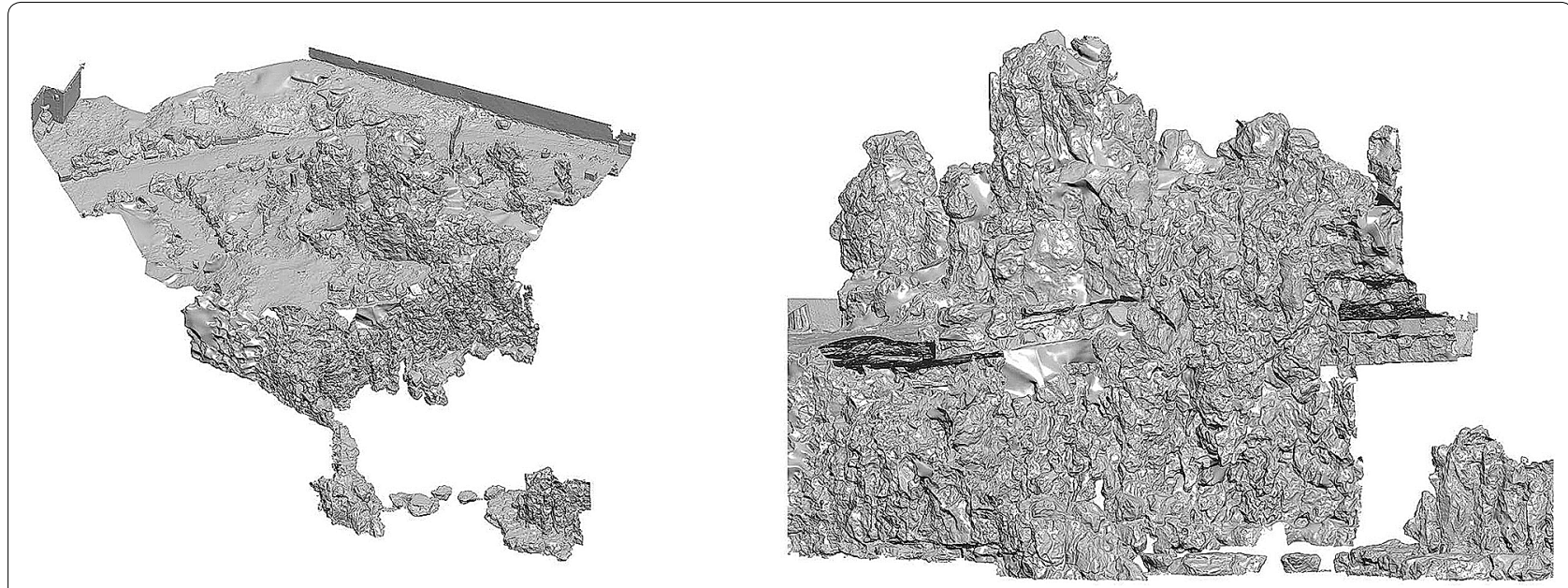

Fig. 8 Final model

rockery and cutting the model down to its printable size (with the range being $13 \mathrm{~m} \times 13 \mathrm{~m}$ and the height at approximately $8 \mathrm{~m}$ ). Since the scanning model is a shell structure, it needs to be thickened to ensure the structure's stability during printing. The necessary thickness can be obtained by extending the edge of the model down to its lowest part, closing it, opening the bottom, and shelling it (Fig. 9). In the scanning process, some areas of the rockery were completely covered by plants; therefore, data could not be obtained. In the preliminary modeling process, the local area appeared smooth after removing the plants. To ensure the data's integrity, the team selected the rock texture suitable for the area to supplement and repair the conditions of

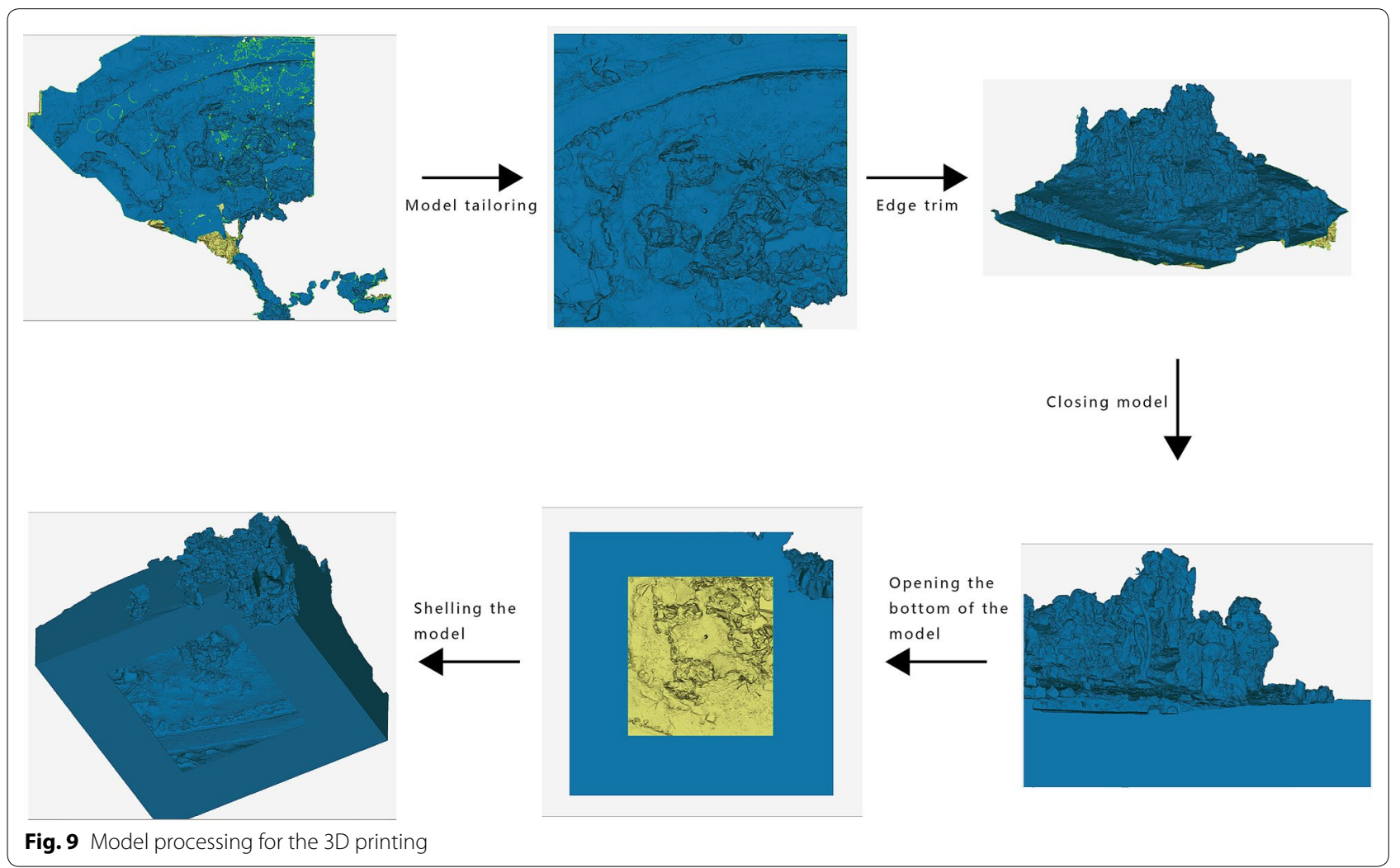


plant-covered rocks onsite. This improved the rockery model (Fig. 10).

The study now turns to 3D printing material selection with SLA (Stereolithography) and FDM (Fuse Deposition Modeling) as the possible printing techniques. In the SLA printing method, the material is photosensitive resin, while for FDM the materials are thermoplastic materials like ABS (Acrylonitrile Butadiene Styrene) or PLA (Polylactic Acid). SLA can achieve a higher level of detail than FDM [26]. Since the rockery featured a high textural complexity, the SLA material was selected for this print. Because of the large volume of rockery, this printing used Union Tech Lite 800 equipment, whose molding size can reach $800 \times 800 \times 550 \mathrm{~mm}$. This allowed the rockery to be printed as a whole, without later splicing, thereby avoiding errors and other problems that may be caused by later splicing. Moreover, the processing accuracy of this print reaches $0.2 \mathrm{~mm}$, which restored the millimeter level point cloud model of 3D scanning to the greatest extent, highlighting the complex shape of the rockery, as well as the surface texture. In the $3 \mathrm{D}$ printing process, there may be some warpage caused by thin areas or a large number of planes. Therefore, the model was thickened, and its edge was pulled down in the model processing stage to make the rockery edge present a right-angled surface, which served to prevent warpage of the model. At the same time, owing to the large volume of rockery and with the goal of avoiding the problem of rockery deformation in the printing process, support was added at the bottom and back of the rockery (Fig. 11). The overall printing time was $48 \mathrm{~h}$. After printing, it took three hours to remove the supports and polish the surface; the final printing cost was $\$ 846$. As this printing was not coated or heattreated, it could be stored for about two years under outdoor exposure. If it is stored indoors and properly kept away from light and humidity, the service life of the model could reach more than 10 years. This project finally produced a $600 \times 600 \times 410 \mathrm{~mm}$ local model of Zhanyuan's South Rockery (Fig. 12). This model accurately reflected the rockery's detailed texture, shape, and informational characteristics, all of which may provide the basis for follow-up research. It proves the mapping method's feasibility (Additional file 1).

In this study, our research object was relatively unique, as scant research had been conducted prior to our study concerning the digital record of Chinese classical gardens, and research on the digital information of rockeries continues even rarer. Our study entails innovative research in this field by digitally recording a rockery and physically reproducing it through $3 \mathrm{D}$ printing.

This study compares the scanning process of the Huanxiu Shanzhuang and Zhanyuan rockeries and summarizes a set of 3D scanning processes that are suitable for a rockery (the selected object of this study) that is stacked with Taihu stone for the main body and has a garden. Because of the small space of the Jiangnan private gardens (which were selected for this study), the rockery had high complexity and constituted a strong representation of a typical rockery. The 3D scanning method for modeling had a compelling universality, as it can also be used in other gardens with large spaces and rockeries with highly complex surfaces.

This study also considers the plant life surrounding the rockery. Previously, the 3D scanning technology used to digitally record China's cultural heritage was a terrestrial 3D laser scanner [32, 34], which had limitations for scanning the rockery's porous structure. This study clearly shows that through the use of hand-held 3D laser scanners, the concave and convex areas, local holes, cracks, and other narrow space areas of the rockery surface are obtainable, which solves the problem of incomplete data

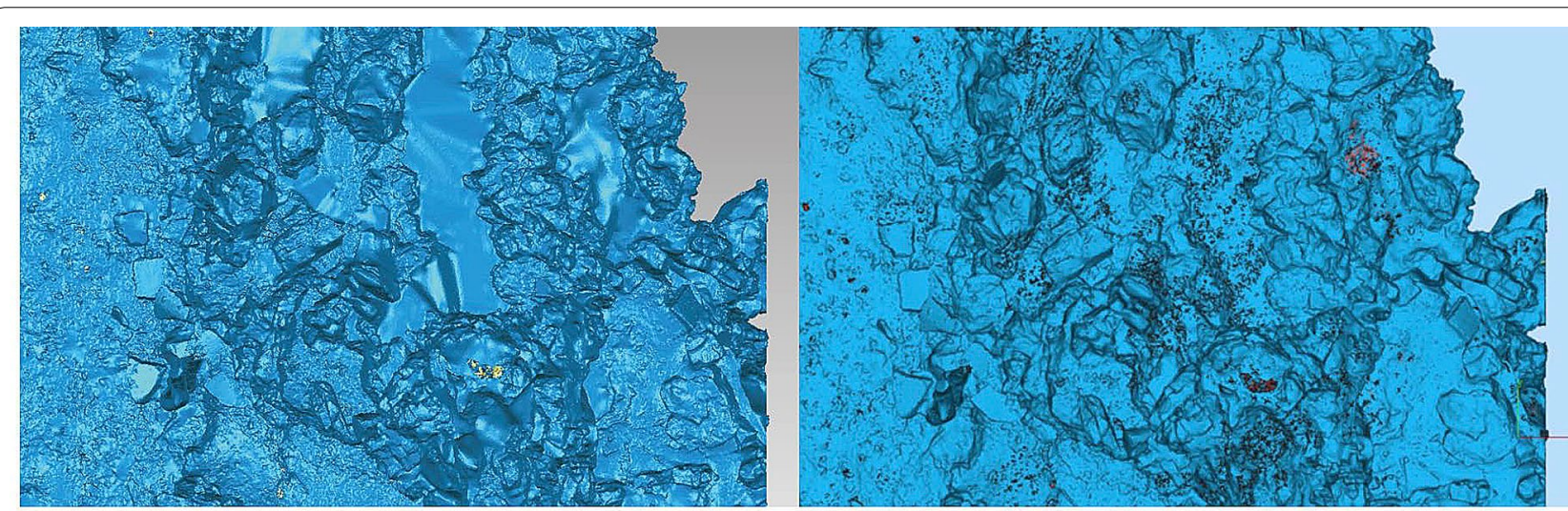

Fig. 10 Model repair (the left side is before repair, and the right side is after repair) 


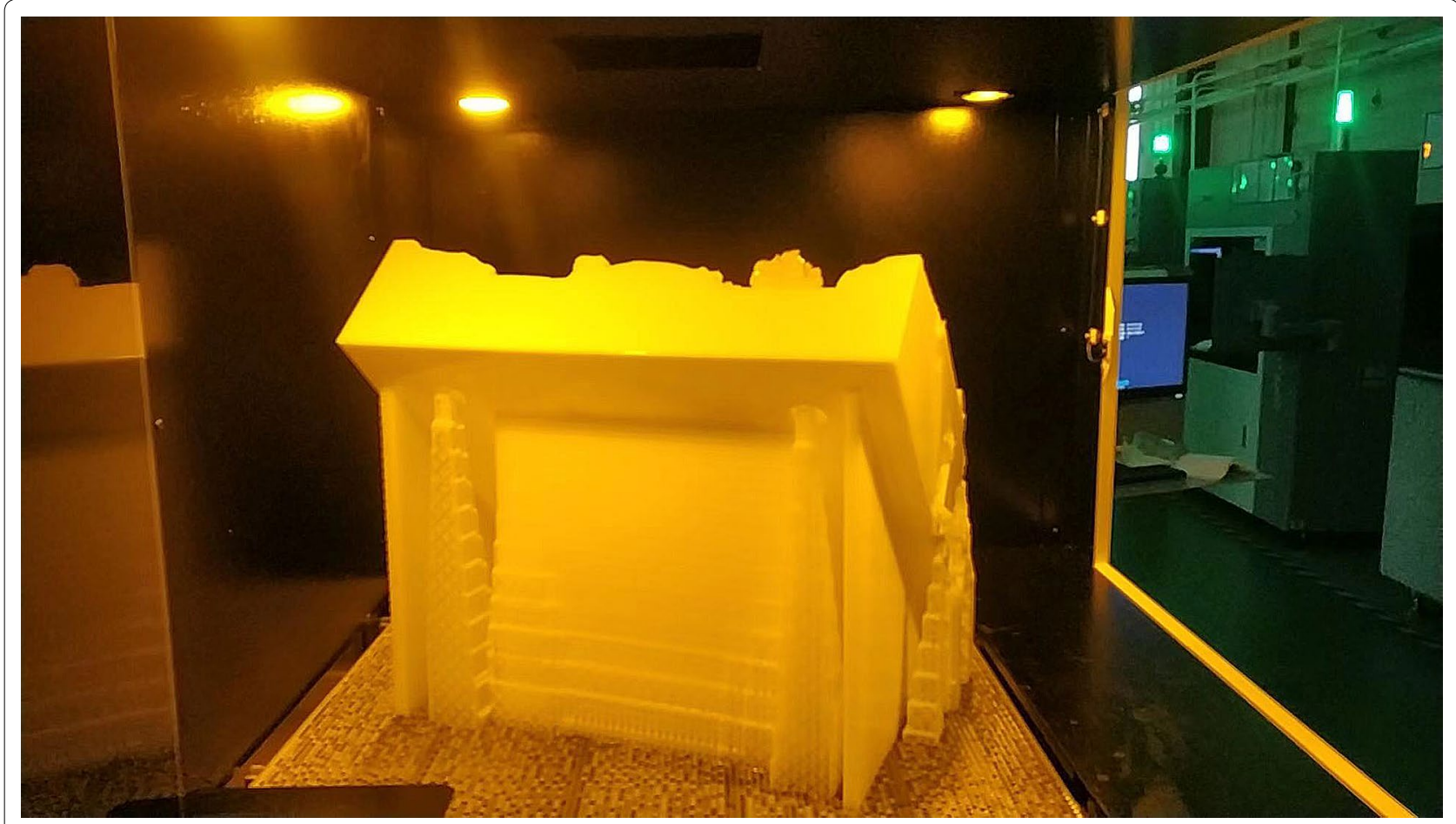

Fig. 11 The structural support behind the model in the printing process

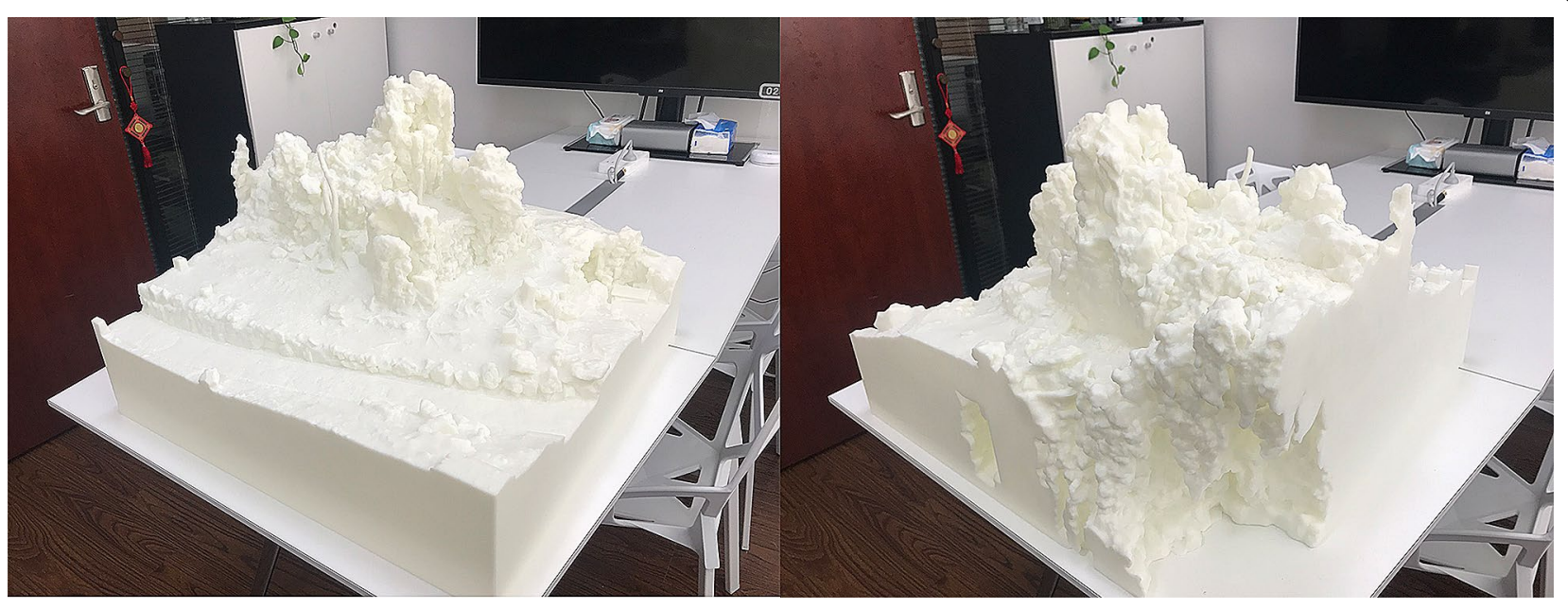

Fig. $123 D$ printed model

caused by the inability of terrestrial 3D laser scanners in these areas.

This study summarizes the scanning experience of Huanxiu Shanzhuang [32], where the target-free 3D laser scanner was used to solve the problem of data missing caused by a target setting failure in some areas. The scanning area was about 7.5 times that of Huanxiu Shanzhuang, but, thanks to the simpler scanning operation, the overall scanning time was reduced from the original 7 days to only $3.5 \mathrm{~h}$. (Table 1 ).

At the same time, this study revealed that, compared with the stand-alone 3D laser scanner, the hand-held 3D laser scanner is more flexible and convenient because of factors such as no target, no stand, a small volume, and a scanning time of $0.4 \mathrm{~h}$ that is shorter than that of the stand-alone. Thus, it is more suitable for people who 
Table 1 Mapping comparison

\begin{tabular}{lll}
\hline Object & Huanxiu Shanzhuang rockeries & $\begin{array}{c}\text { Zhanyuan's } \\
\text { South } \\
\text { Rockery }\end{array}$ \\
\hline Equipment & & Trimble TX8 \\
Number of scanning stations & Leica ScanStation C10 & 154 \\
Number of scanning targets & 22 & 0 \\
Is manual point cloud splicing required? & 10 & No \\
Scan time & Yes & $3.5 \mathrm{~h}$ \\
Scan range & 7 days & $\sim 750 \mathrm{~m}^{2}$ \\
\hline
\end{tabular}

need fast 3D scanning of rockeries. However, the accuracy of the data is lower than that of the stand-alone 3D laser scanner; thus, it is suitable for the rapid acquisition of data in complex areas such as a rockery and complementary to the data of stand-alone 3D laser scanner as auxiliary data. (Table 2).

In the later stage of data processing, TRW was adopted to process the target-free, fully automatic splicing data. The automatic splicing was realized through the overlapping areas between the point clouds obtained in the earlier stage. This solved problems such as coordinate confusion caused by an error in target setting; there were no problems such as the interpenetration of stones or a crisscross of the front and the back; thus, the accuracy of the data had been greatly improved.

In this study, the rockery was reproduced by 3D printing with the hope that Chinese classical gardens will continue to be reproduced in this way so that the previously original, unrepeatable garden space will be physically recorded. Furthermore, since the research on the $3 \mathrm{D}$ scanning and printing of buildings is relatively developed in the literature, we hope that the buildings around the rockery can also be scanned and printed in 3D at a later stage to create a complete garden space. However, $3 \mathrm{D}$ scanning technology is not ideal for processing plants because of the density and complexity of leaves and branches. Thus, many plant models cannot be adequately presented yet. Also, the rockery's 3D print is a white model without coloring. Currently, most 3D printing equipment cannot make direct color copies; therefore, manual coloring is needed [26], also there are some cases of color 3D printing, but the price is relatively high [35, 36]. This process, however, still cannot reflect the texture of the rockery. In the field of 3D scanning and 3D printing, new methods are continuously emerging, and these problems will eventually be solved.

\section{Conclusion}

Increasingly, attention has been paid to digital cultural heritage and the digital research of Chinese classical garden rockeries. However, in the face of diverse digital instruments, many questions arise, such as how to use digital methods for research or utilize data to protect and activate cultural heritage. In recent years, 3D printing technology has rapidly developed and made important contributions to cultural heritage [21, 27]. Through 3D printing, we hope to activate research for the rockery that belongs to a heritage site by improving people's intuitive understanding of the rockery through physical visualization. Similarly, 3D printing can also be used to enable a

Table 2 Comparison of working parameters

\begin{tabular}{lll}
\hline Equipment & Trimble TX8 & Slam_Horizon \\
\hline Scanning range & $\geq 335 \mathrm{~m}$ & $100 \mathrm{~m}$ \\
Measuring speed & $\geq 1,000,000$ point/second & 300,000 point/second \\
Measuring accuracy & $1 \mathrm{~mm}$ & $10 \sim 30 \mathrm{~mm}$ \\
Collection object & Main rockery & Narrow cave, crevice, hole \\
Acquisition time & $3.5 \mathrm{~h}$ & $40 \mathrm{~min}$ \\
Point cloud processing duration & 8 days & 0.5 days \\
Point cloud classification duration & $1 \mathrm{~h}$ & $0.5 \mathrm{~h}$ \\
Grid model generation time & 6 days & 0.5 days \\
Model processing time & 6 days & 2 days \\
Point cloud quantity & 1.66 billion & 320 million \\
\hline
\end{tabular}


rockery's industrialization or even place it into cultural and creative industries for production to increase its value.

This experiment involved the use of two different 3D scanning devices to scan the rockery and print the model at the same time in order to realize the reproduction of the rockery. Doing so provided a new method and direction for the future protection and research of the rockery. Compared with the experiment conducted by the team in Huanxiu Shanzhuang [32], the scanning time and accuracy were improved. For the rockery, a more specific and perfect mapping process plan has been formed. However, this mapping method is developed for the high-precision data needed for 3D printing. The number of points acquired in this experiment was too large to ensure the comprehensiveness of the data acquisition. In the later modeling process, the operation was complex, the computer operation was difficult, and the data processing time was long. Questions remain about how to ensure the validity of the data and avoid the post-processing difficulties caused by redundant data. For example, if only the rockery is digitally recorded, and high-precision model research is not needed, the hand-held 3D laser scanner can achieve fast, convenient operation with less point cloud data, which is convenient for later modeling. However, this method does not solve all problems. In the process of scanning, it is still the case that plant occlusion is an important factor affecting scanning accuracy. In this experiment, there were still some models in some areas that were difficult to repair because of plant occlusion. This may be solved in the future by upgrading the equipment and improving the mapping method.

In terms of cultural relic protection, this study lays the foundation for high-precision maintenance and settlement monitoring of rockeries. The team will strive to carry out regular high-precision 3D scanning of rockeries in the future and will endeavor to establish a digital protection network system for rockeries, so as to change their protection status from rescue protection to preventive protection. In terms of teaching and research, the team plans to carry out mechanical analysis and digital disassembly of the obtained rockery model, complete the simulation process of rockery through the computer, and help students to carry out virtual simulation learning about rockery construction. Furthermore, this study aimed to provide a method for preserving other stone cultural heritage sites that are similar to rockeries (such as those with complex voids and spaces). By further improving this method, researchers may eventually record even more stone cultural heritage sites.

Aiming at the problem of whether the 3D printed rockery obtained in this experiment has research accuracy and provides researchers with secondary research, the team plans to scan the 3D model obtained to compare whether it matches the original rockery data. Doing so will confirm the accuracy of the model. The success of such endeavors may be inhibited by the limitations of this work; this experiment did not collect and print the color of the rockery. The white model will have a certain impact on the visibility of the original texture of the rockery. Although SLA material can restore the details of the rockery to a great extent, it does not completely restore the original texture of Taihu stone. Such lack of detail will have an impact on the study of the rockery learners have a certain influence. This limitation can be addressed by trying to obtain other materials closer to the stone's texture, and coloring the rockery, perhaps through color printing or by projecting an image on the model's surface to mimic the texture.

In recent years, 3D printing has been utilized to protect cultural relics. For example, to prevent damage to cultural relics caused by natural conditions and other factors, 3D copies are used for permanent replacement [38] or while auxiliary cultural relics are restored $[39,40]$. This work does not intend to advocate using 3D printing to repair and replace the rockery. However, in the future, it may be possible to disassemble the entire rockery by having 3D prints of the rockery's constituent parts; this will allow researchers to restore the stacking process. Also, 3D printed rockeries can help people with visual impairment to have more intuitive contact with the site and can reduce the rockery as a whole to a smaller range so that people can appreciate and connect with it when the original cannot be accessed. This may attract more tourists and increase the site managers' interest.

\section{Supplementary information}

Supplementary information accompanies this paper at https://doi. org/10.1186/s40494-020-00405-z.

Additional file 1. Model of Zhanyuan's South Rockery.

\section{Abbreviations}

UAV: Unmanned Aerial Vehicle; TRW: Trimble Real Works; SLA: Stereolithography; FDM: Fused Deposition Modeling; ABS: Acrylonitrile Butadiene Styrene; PLA: Polylactic Acid.

\section{Acknowledgements}

Not applicable.

\section{Authors' contributions}

QD was responsible for most of the work and writing of the article. QZ was responsible for the review and revision of articles. LZ was responsible for the work of the HS. All authors read and approved the final manuscript.

\section{Funding}

This work is supported by the China National Nature Fund [51878353]; Humanities and Social Sciences Fund of the Ministry of Education of China [18YJAZH132]. 


\section{Availability of data and materials}

The dataset supporting the conclusions of this article is included within the article (and its additional file).

\section{Competing interests}

The authors declare that they have no competing interests.

Received: 17 March 2020 Accepted: 13 June 2020

Published online: 27 June 2020

\section{References}

1. Murck A, Fong W. A Chinese garden court: The astor court at the metropolitan museum of art. New York: Metropolitan Museum of Art; 1980

2. Yu K, Del Tredici P. Infinity in a bottle gourd: understanding the Chinese garden. Arnoldia. 1993;53:2-7.

3. Paolillo M. Forging the garden: The "Yuanye" and the significance of the Chinese garden in the 17th century. East and West. 2003;53:209-39.

4. Keswick M, Jencks C, Hardie A. The Chinese garden: History, art and architecture. Cambridge: Harvard University Press; 2003.

5. Parkes G. Thinking rocks, living stones: reflections on Chinese Lithophilia. Diogenes. 2005;52:75-87.

6. Aplin G. World heritage cultural landscapes. Int J Heritage Stud. 2007;2007(13):427-46.

7. Assali P, Grussenmeyer P, Villemin T, Pollet N, Viguier F. Surveying and modeling of rock discontinuities by terrestrial laser scanning and photogrammetry: semi-automatic approaches for linear outcrop inspection. J Struct Geol. 2014;2014(66):102-14.

8. HernándezClemente R, NavarroCerrillo R, Ramírez F, Hornero A, ZarcoTejada P. A novel methodology to estimate single-tree biophysical parameters from 3D digital imagery compared to aerial laser scanner data. Remote Sensing. 2014;6:11

9. Zlot R, Bosse M, Greenop K, Jarzab Z, Juckes E, Roberts J. Efficiently capturing large, complex cultural heritage sites with a handheld mobile 3D laser mapping system. J Cult Herit. 2014;2014(15):670-8.

10. Qingping Zhang, Huilin Liang, Weizheng Li, et al. Research of the application of digital survey techniques in private garden. J Nanjing Forestry University (Natural Science Edition). 2018;42(1):1-6. https://doi.org/10.3969/j. issn.1000-2006.201704029.

11. Chen Yang, Feng Han. Digital heritage landscape: research on spatial character of the grand rockery of yuyuan garden in Shanghai based on 3D point cloud technologies. Chinese Landscape Architect. 2018;34(11):20-4. https://doi.org/10.3969/j.issn.1000-6664.2018.11.005.

12. Ning Wen. Research on Rockery Space of Jingyi Garden. Xiangshan Park: North China University of Technology; 2018.

13. Chen Wanyu. Based on ANSYS Beijing Royal Garden Bluestone Rockery Research. North China University of Technology; 2019.

14. The Operational Guidelines for the Implementation of the World Heritage Convention. 2013. http://whc.unesco.org/en/guidelines. Accessed 12 May 2020.

15. Zanola, S. Fabrikant, Sara I. Çöltekin, A. The Effect of Realism on the Confidence in Spatial Data Quality in Stereoscopic 3D Displays. In Proceedings of the 24th International Cartographic Conference (ICC 2009), Santiago, Chile, 15-21 November 2009, p. 1-9. https://doi.org/10.5167/uzh-27017.

16. SOUTH KENSINGTON MUSEUM. Convention for Promoting Universally [the] Reproduction of Works of Art for the Benefit of Museums of All Countries. In Catalogues of Reproductions of Objects of Art, in Metal, Plaster, and Fictile Ivory, Chromolithography, Etching, and Photography: 1867. p.184

17. Neumüller M, Reichinger A, Rist F, Kern C. 3D Printing for Cultural Heritage: Preservation, Accessibility, Research and Education. In: Ioannides M, Quak E, editors. 3D Research Challenges in Cultural Heritage. Lecture Notes in Computer Science. Berlin/Heidelberg: Springer; 2014. p. 119-134.

18. M. Balzani, M. Callieri, M. Fabbri, A. Fasano, C. Montani, P. Pingi, Digital representation andmultimodal presentation of archeological graffiti at Pompei, Proceedings of 5th International Symposium on Virtual Reality, Archaeology and Intelligent Cultural Heritage VAST 2004, Brussels and Oudenaarde, Belgium, 7-10 December, p. 1-11. https://doi.org/10.2312/ vast/vast04/093-103.
19. T. Allard, M. Sitchon, R. Sawatzky, R. Hoppa, Use of hand-held laser scanning and 3D printing for creation of a museum exhibit, Proceedings of 6th International Symposium on Virtual Reality, Archaeology and Cultural Heritage VAST 2005: Short and Project Papers, Goslar, Germany, November 2005; p. 97-101.

20. M. Cooper, A. La Pensée, J. Parsons, The use of laser scanning and rapid manufacturing techniques for museum exhibitions, Proceedings of 7th International Symposium on Virtual Reality, Archaeology and Cultural Heritage, Nicosia, Cyprus; January 2006. p. 65-71.

21. Xu J, Ding L, Love PED. Digital reproduction of historical building ornamental components: from 3D scanning to 3D printing. Autom Constr. 2017;76:85-96.

22. Bigliardi G, Dioni P, Panico G. Restauro e innovazione al Palazzo Ducale di Mantova: la stampa 3D al servizio dei Gonzaga. Archeomatica. 2015;6:34-7.

23. P. Brimblecombe, C.M. Grossi, Damage to buildings from future climate and pollu- tion, APT Bull. 38 (2/3) (2007) 13-18. https://www.researchga te.net/publication/ 271846514. Accessed 12 May 2020.

24. Oliveira DV, Lourenço PB, Lemos C. Geometric issues and ultimate load capacity of masonry arch bridges from the northwest Iberian Peninsula. Eng Struct. 2010;32(12):3955-65. https://doi.org/10.1016/j.engst ruct.2010.09.006

25. Lim K, Loo Z, Goldie S, Adams J, McMenamin P. Use of 3D printed models in medical education: a randomized control trial comparing 3D prints versus cadaveric materials for learning external cardiac anatomy. Anatomical Sci Educ. 2016;9(3):213-21. https://doi.org/10.1002/ase.1573.

26. Balletti $C$, et al. 3D printing: state of the art and future perspectives. J Cult Heritage. 2017;26:172-82. https://doi.org/10.1016/j.culher.2017.02.010.

27. Themistocleous, K.; loannides, M.; Agapiou, A.; Hadjimitsis, D.G. The methodology of documenting cultural heritage sites using photogrammetry, UAV, and 3D printing techniques: The case study of Asinou Church in Cyprus. In Proceedings of the Third International Conference on Remote Sensing and Geoinformation of the Environment (RSCy2015), Paphos, Cyprus, 16-19 March 2015; SPIE: Bellingham, WA, USA; Volume 9535, p. 953510:1-953510:7.

28. Colomina, I. and Molina, P. Unmanned aerial systems for photogrammetry and remote sensing: a review. ISPRS J. of Photogram. and Rem. Sens 2014; 92:79-97. https://doi.org/10.5281/zenodo.57983.

29. Wabiński J, Mościcka A. Natural heritage reconstruction using full-color 3D printing: a case study of the valley of five polish ponds. Sustainability. 2019;11(21):5907. https://doi.org/10.3390/su11215907.

30. Lerma JL, Navarro S, Cabrelles M, Villaverde V. Terrestrial laser scanning and close range photogrammetry for 3D archaeological documentation: the Upper Palaeolithic Cave of Parpalló as a case study. J Archaeol Sci. 2010;37(3):499-507. https://doi.org/10.1016/j.jas.2009.10.011.

31. Remondino F. Heritage recording and 3D modeling with photogrammetry and 3D scanning. Remote Sens. 2011;3(12):1104-38. https://doi. org/10.3390/rs3061104

32. Liang $\mathrm{H}$, et al. The integration of terrestrial laser scanning and terrestrial and unmanned aerial vehicle digital photogrammetry for the documentation of Chinese classical gardens-A case study of Huanxiu Shanzhuang, Suzhou, China. J Cult Heritage. 2018;33:222-30. https://doi. org/10.1016/j.culher.2018.03.004.

33. Guxi Pan. The Art of Jiangnan Scenery. Nanjing: Southeast University Press; 2001.

34. Xu Z, Wu L, Shen Y, Li F, Wang Q, Wang R. Tridimensional reconstruction applied to cultural heritage with the use of camera-equipped UAV and terrestrial laser scanner. Remote Sens. 2014;6(11):10413-34. https://doi. org/10.3390/rs61110413.

35. Rase W-D. Creating Physical 3D Maps Using Rapid Prototyping Techniques. In: Buchroithner M.F. editor. True-3D in Cartography. Lecture Notes in Geoinformation and Cartography. Berlin/Heidelberg: Springer; 2012. p. 119-134

36. Wabiński J, Mościcka A. Natural heritage reconstruction using full-color 3D printing: a case study of the valley of five polish ponds. Sustainability. 2019;11:5907.

37. Themistocleous, K.; loannides, M.; Agapiou, A.; Hadjimitsis, D.G. The methodology of documenting cultural

heritage sites using photogrammetry, UAV, and 3D printing techniques: The case study of Asinou Church in Cyprus. In Proceedings of the Third International Conference on Remote Sensing and Geoinformation of the 
Environment (RSCy2015), Paphos, Cyprus, 16-19 March 2015. https://doi. org/10.1117/12.2195626.

38. Basilica di San Petronio Project. 2013. http://www.factum-arte.com/ pag/593. Accessed 12 May 2020.

39. Santopuli N, DeCrescenzio F, Fantini M, Persiani F, Seccia L. L'Ebe del Canova: modello digitale e sviluppi applicativi. Archeomatica. 2010;1:40-3.

40. Arbace L, Sonnino E, Callieri M, Dellepiane M, Fabbri M, Idelson Al, Scopigno R. Innovative uses of 3D digital technologies to assist the restoration of a fragmented terracotta statue. J Cult Herit. 2013;14(4):33245. https://doi.org/10.1016/j.culher.2012.06.008.

\section{Publisher's Note}

Springer Nature remains neutral with regard to jurisdictional claims in published maps and institutional affiliations.

\section{Submit your manuscript to a SpringerOpen ${ }^{\odot}$ journal and benefit from:}

- Convenient online submission

- Rigorous peer review

- Open access: articles freely available online

- High visibility within the field

- Retaining the copyright to your article

Submit your next manuscript at $\boldsymbol{\nabla}$ springeropen.com 